\title{
Analysis of technical efficiency of potato (Solanum tuberosum L.) production in Chilga District, Amhara National Regional State, Ethiopia
}

\author{
Agerie Nega Wassihun * (D), Tigabu Dagnew Koye and Abebe Dagnew Koye
}

${ }^{*}$ Correspondence:

agerie.nega@yahoo.com

Department of Agricultural

Economics, College

of Agriculture

and Environmental Sciences,

University of Gondar,

P.O.Box 196, Gondar, Ethiopia

\begin{abstract}
Background: Potato is one of the major staple crops in the Eastern and Central Africa sub-region. Its importance continues to rise due to increased urbanization and demand for potato is projected. This increase will definitely come with its share of challenges that need to be addressed. This study was aimed to measure the level of technical efficiency, yield loss due to inefficiency and identify the factors that influence the efficiency levels of potato producers' in Chilga District. Primary data were collected from 150 farmers selected using multistage sampling procedure and analyzed using descriptive statistics, a parametric stochastic frontier production function models.
\end{abstract}

Results: The results of the study indicated that the minimum, maximum and average yields of potato production in the sample households were 1000, 36,000 and $13,108 \mathrm{~kg} / \mathrm{ha}$, respectively. The stochastic frontier and Cobb-Douglas functional form with a one-step approach was employed to analyze efficiency and factors affecting efficiency in potato production. The mean technical efficiency (TE) was found to be $46 \%$, and about $17,782.43 \mathrm{~kg}$ of potato output per hectare was lost due to inefficiency factors implying there is a room for improvement in technical efficiency by $54 \%$ with the present technology. The Stochastic Production Frontier (SPF) result revealed that DAP at $5 \%$ and Oxen, MDE and seed at $1 \%$ probability level significantly influencing potato production. The socio-economic variables that exercised important role for variations in technical efficiency positively were age and improved seed and nevertheless distance to market was found to increase inefficiency significantly among farm household.

Conclusions: There is considerable difference in the efficiency level among plots. Hence if inputs are used to their maximum potential, there will be considerable gain from improvement in technical efficiency. The estimated SPF model together with the inefficiency parameters shows that age and improved seed variety were influenced by inefficiency negatively whereas distance to market increased the level of technical inefficiency.

Keywords: Chilga district, Cobb-Douglas, Potato, SPF, Technical efficiency, Yield loss 


\section{Background}

Potato (Solanum tuberosum L.) is one of the major staple crops in the Eastern and Central Africa (ECA) sub-region and its importance continues to rise due to increased urbanization and uptake of processed potato products such as French fries (chips) and crisps. Demand for potatoes in sub-Saharan Africa is projected to have a $250 \%$ increase between 1993 and 2020, with an annual growth in demand of 3.1\% and the growth in area under production is estimated at $1.25 \%$ a year (Scott et al. 2000). In Ethiopia, potato production ranks first in its volume of production and consumption followed by cassava, sweet potato and yam. It has a huge potential to contribute for the national economy, improve food security and income for smallholder farmers through its value-added products (Tiruneh et al. 2017). Moreover, the return on cash investment was more than $100 \%$ which enables growers reduce cash losses and the return on family labor was higher than the opportunity cost of work (Gildemacher et al. 2009).

Agricultural production and productivity in Ethiopia are very low and the growth in agricultural output has barely kept pace with the growth in population. In most part of Ethiopia grains production meets the needs of the people including in the deficit areas. But, the inefficient agricultural systems and differences in efficiency of production discourage farmers to produce more (Aseyehegn et al. 2012). In Ethiopia highlands potato holds great promise for improving the livelihoods of millions of smallholder farmers. The high yield, early maturity, and excellent food value give the potato crop great potential for improving food security, increasing household income, and reducing poverty (Bizuayehu 2014). Due to short vegetative period it allows farmers to find an appropriate season for its cultivation under a wide range of weather patterns and less predictable climates. As a result, the combined area planted to potato in Ethiopia for both Belg (short rainy season-February to May) and Meher (long rainy season-from June to October) growing seasons is about 179,000 ha (CSA 2014). In spite of its popularity, the productivity of the crop is relatively low (CSA 2014). There are many factors contribute to the low yield, including drought, frost, poor production practices and limited access to high quality seed (Doss et al. 2008; FAO 2010; Mulatu et al. 2005; Gildemacher et al. 2009; Hirpa et al. 2010).

In Ethiopia, potato is grown in four major areas: The Central, Eastern, North-Western and Southern regions, which together constitute approximately $83 \%$ of the potato farmers in the country (CSA 2011). In the Central area, potato production includes the highland areas surrounding the capital, i.e., Addis Ababa. In this area the major potatogrowing zones are West and North Shewa. About 10\% of the potato farmers are located in this area (CSA 2009). In the central area potato is produced mainly in the belt (short rain Season-February to May) and meher (long rain Season-June to October) periods. Potato is also grown off-season under irrigation (October to January). Because of the cool climate and access to improved varieties, farmers in this area of the country also produce potatoes which are sold to other farmers in the vicinity or to NGOs and agricultural bureaus to be disseminated to distant farmers. In the central area, farmers grow about seven local varieties, eight improved varieties and six clones (i.e., genetic material which is not officially released) (Hirpa et al. 2010). The Eastern area of potato production mainly covers the Eastern highlands of Ethiopia, especially the East Harerge zone. However, the area is identified specifically because the majority of the potato 
farmers' in this region produce potatoes for the market and the farmers have also access to export markets in Djibouti and Somalia. Potato is mainly grown under irrigation in the dry season (December to April). This season is characterized by low disease pressure and relatively high prices (Mulatu et al. 2005). The North-Western area of potato production is situated in the Amhara region. It is the major potato growing area in the country, accounting for about $40 \%$ of the potato farmers. South Gonder, North Gonder, East Gojam, West Gojam and Agew Awi are the major potato production zones in this region (Deressa et al. 2017).

According to the Global Hunger Index (2013), levels of hunger are still "alarming" or "extremely alarming" in 19 countries, including Ethiopia, meaning food security is an urgent issue. Potato has great potential when it comes to food security (UNDP 2014). Thus, among the crops that have increasingly gained importance to overcome food insecurity problems in Ethiopia is potato. The potential of potato for food security is increasingly being noticed as witnessed by growing interest of private investors and policy makers in this crop. In recent years, potato production has expanded because of the availability of improved technologies, expansion of irrigation structure and increasing market value (EIAR and ARARI, 2013). However, the average yield in Ethiopia reaches only 7 tons/ha when the potential for smallholder is around 25 tons/ha (EIAR and ARARI 2013). Furthermore, as cited in EIAR and ARARI (2013), for Sub-Saharan Africa (SSA), Scott et al. (2000) projected a 250\% increase in demand for potato between 1993 and 2020, with an annual growth of 3.1\%. The growth in area under production is estimated at $1.25 \%$ a year, the rest of the increase being achieved through predicted growth in productivity. Increased potato productivity will play a buffer role to the increasing food prices; thus, enhance household income in the project countries with a spill over to other countries in SSA (Dube et al. 2018). But generally believed that resources in the agricultural sector, especially in under-developed countries are being utilized inefficiently (Ahmad et al. 2006). Even though several studies have been conducted on technical efficiency of crops including potato in Ethiopia, according to literature review, technical efficiency of potato farming is still insignificant and very little is known whether smallholder potato growers are efficient or not in Chilga district. Moreover, as to the best of the author's knowledge and belief, there were no similar studies undertaken in the study area. Some of studies conducted are: Abate et al. (2019) on Technical efficiency of smallholder farmers in red pepper production in North Gondar Zone; Dube et al. (2018) on Technical efficiency and profitability of potato production by smallholder farmers in Bale Zone of Ethiopia; Demelash (2015) on Deficit irrigation scheduling for potato production in North Gondar zone; Tiruneh et al. (2017) on Technical efficiency determinants of potato production in Welmera district, Oromia. Therefore, this study was investigated to fill this gap with the aim of analyzing technical efficiency of potato production and its determinant factors in Chilga district of Central Gondar Zone.

\section{Research methodology}

\subsection{Description of the study area}

This study was conducted in Chilega District in North Gondar Zone of Amhara Regional State, Ethiopia (Fig. 1). Chilga District was selected purposively based on its potential in potato production. It is one of the districts in North Gondar Zone and an important 


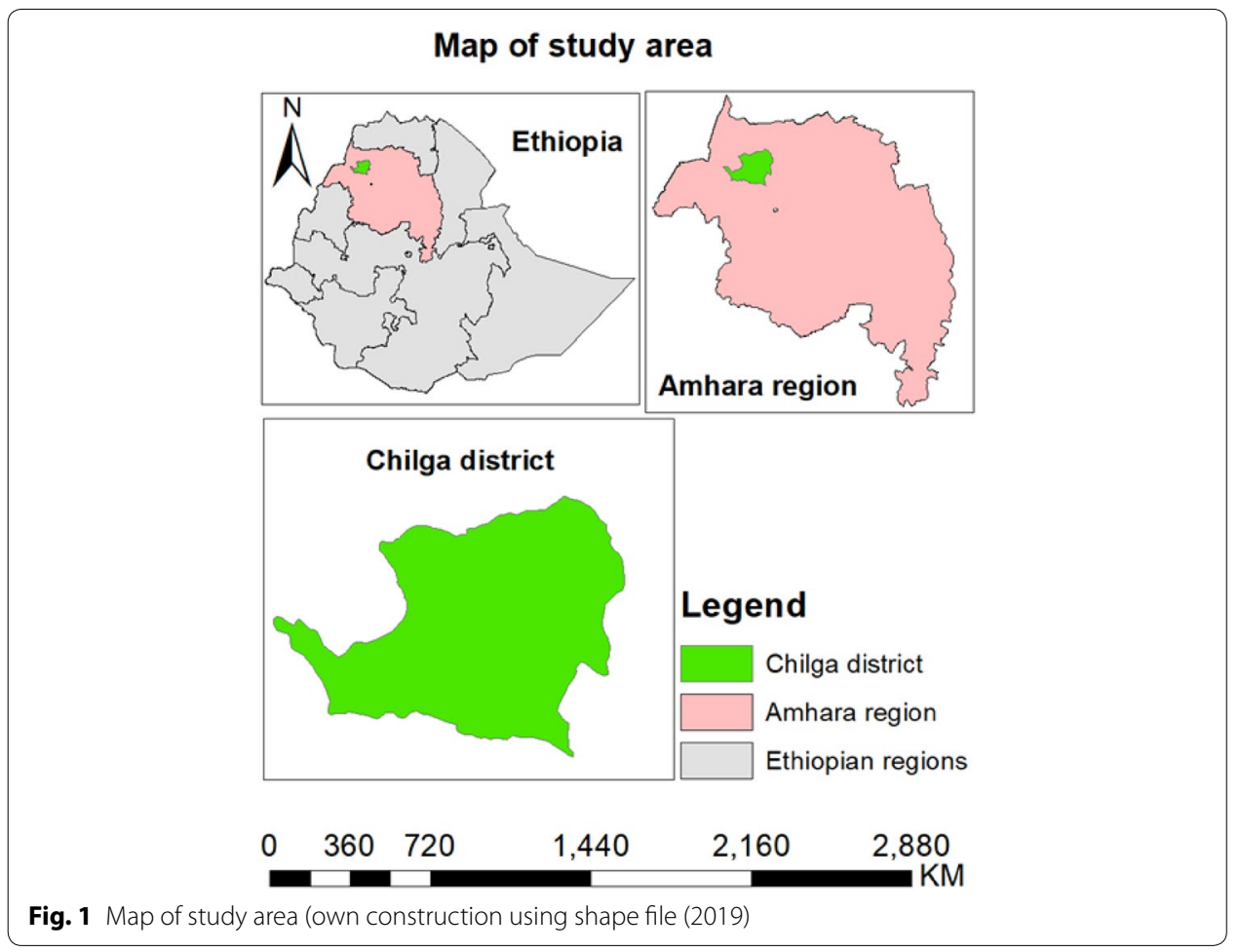

stopping point on the historic Gondar-Sudan trade route and is located $61 \mathrm{~km}$ west of Gondar town on the way to Metema. Chilga District is bordered in south by Takusa, in west by Metema, in the north by Tach Armachiho, in the northeast by Lay Armachiho, and in the east by Dembia. Other towns in Chilga District include Seraba and Wohni. The District's elevation ranges between 1000 and $1500 \mathrm{~m}$ above sea level. The agro-ecology of District is $67 \%$ and 33\% Kola and Woinadega, respectively. The annual rain fall of the District is between 995 and $1175 \mathrm{~mm}$ and the mean daily average temperature is $27^{\circ} \mathrm{C}$. A survey of the land in this district shows that $21.7 \%$ is arable or cultivable, 1.9 is pasture, $22.3 \%$ is forest or shrub-land, and the remaining $54.1 \%$ is considered degraded or other. Based on 2007 national census conducted by the Central Statistical Agency of Ethiopia (CSA), the District has a total population of 221,462, an increase of $33.34 \%$ over the 1994 census, of whom 112,054 are men and 109,408 women; 20,745 or $9.37 \%$ are urban inhabitants while the reaming $90.63 \%$ live in rural areas. The District has 48 kebeles in which 41 are rural and 7 are urban kebeles. The District has total area of 3071.65 square kilometers and population density of 72.10 persons per square kilometer, which is greater than the Zone average of 63.76 persons per square kilometer. A total of 47,336 households were counted in this District, resulting in an average of 4.68 persons to a household, and 45,352 housing units. The majority of the inhabitants practiced Ethiopian Orthodox Christianity, with $96.7 \%$ reporting that as their religion, while $3.1 \%$ of the population said they were Muslim (CDFEDO 2014).

\subsection{Sampling technique and sample size}

Multistage stage sampling procedure was employed when selecting sample respondents. In the first stage, out of 41 potato producer rural kebelles in Chilga district, 16 
kebeles that are the major potato producers were selected purposively. In the second stage, from 16 kebeles 4 kebeles were selected randomly. In the third stage, based on a complete list of the name of all potato producer farmers obtained from Development Agent (DA) during 2015/16 production year, 150 households were selected using systematic random sampling considering probabilities proportional to size. For this study to obtain a representative sample size, for cross-sectional household survey sample size determination formula developed by Kothari (2004) was used as follows:

$$
n=\frac{Z^{2} p q}{e^{2}}=\frac{1.96 \times 0.5 \times 0.5}{0.08^{2}}=150
$$

where $n$ is the sample size; $Z$ is the confidence level $(\alpha=0.05$, hence, $Z=1.96) ; p$ is the proportion of the population containing the major interest, $q=1-p$ and $e$ is the allowable error.

Table 1 shows the list of sample kebles, number of potato producer households in each KA and sample households taken from each KA.

\subsection{Data type, sources and method of data collection}

Both primary and secondary data were used for the study. Primary data were sourced through interviews with potato producers using a structured interview schedule. To facilitate the task of data collection, the enumerators were recruited and trained for a day to master the research and the data collection tools. Interview schedule was pretested with the enumerators for 1 day to ensure that wording and coding matched field situation. The interview schedule questionnaire captured data on farmers potato production levels/total amount of output and production related socio-economic factors. That is to say, data were collected on input-output variables such as labor (MDE), oxen (ODE), farm size in ha, fertilizer in $\mathrm{kg}$ (DAP and Urea) and seed in $\mathrm{kg}$ and also data were collected on socio-demographic factors such as age, level of education, access to credit, household size, frequency of extension contact, DAP availability on time, Urea availability on time, seed availability on time, soil conservation activities, potato seed varieties, distance to input/output market, off farm activities, total livestock (TLU), training on production and marketing. Secondary data was sourced from different published and unpublished sources like research findings on technical efficiency of various economic activities.

Table 1 Potato growing farmers and sample size. Source: Chilga District Agricultural office, 2015/2016

\begin{tabular}{lccc}
\hline Kebeles & Total households & Sample size & Percent \\
\hline Eyaho-Serba & 345 & 40 & 26.6 \\
Sertiya-Warkaye & 332 & 38 & 25.6 \\
Teber-Serako & 276 & 32 & 21.2 \\
Anguaba-Buladigie & 345 & 40 & 26.6 \\
Total & 1298 & 150 & 100 \\
\hline
\end{tabular}




\section{Methods of data analysis}

\subsection{Descriptive statistics}

To get some insight about the characteristics of the sampled farm households, descriptive statistics was used. Descriptive statistical analysis was employed to analyze the survey data using measures of dispersion such as percentage, frequency and measures of central tendency such as mean and standard deviation.

\subsection{Econometrics analysis}

Several functional forms have been developed to measure the physical relationship between input and output. The most common functional forms are Cobb-Douglas and transcendental logarithmic (translog) function. The Cobb-Douglas is the simpler but less flexible, form is very parsimonious with respect to degrees of freedom (Leavy et al. 1999).

However, one of the drawbacks of the Cobb-Douglas is that it is less flexible as it imposes severe priori restriction on the farm's technology by restricting the production elasticity to be constant and elasticity of input substitution to unity (Wilson and Hadley 1998).

The translog production function on the other hand is a more flexible functional form than the Cobb-Douglas, which takes into account the interactions between variables and allows for non-linearity in the parameters. However, the translog suffers some drawbacks. First, it does not yield coefficients of a plausible sign and magnitude due to the degrees of freedom and second, when estimating the translog production function, multicollinearity among explanatory variables is usually present (Leavy et al. 1999). From the above literature review one can understand that unless we use test of hypothesis to choose either of them, no one can say one better than the other. In this study test of hypothesis was employed to select either of them.

The Cobb-Douglas has been widely used in many empirical studies particularly those related to developing countries for farm efficiency analysis (Bravo-Ureta and Pinheiro 1997). The function is formulated as:

$$
Y=(\text { Lab, SD, Frmsze, DAP, Urea, Oxen) }
$$

where $Y$ is the potato output produced in $\mathrm{kg}$. The variable Frmsze represents farm area planted to potatoes, Lab means family and hired labor measured in man-days, SD represents the quantity of seed in kilograms, DAP and Urea measured in kilograms and Oxen it is measured in oxen-days.

Following Jondrow et al. (1982), technical efficiency estimation is given by the mean of the conditional distribution of inefficiency term $U_{i}$ given $\varepsilon$; and thus defined by:

$$
E\left(u_{i} \mid \varepsilon_{i}\right)=\frac{\delta_{u} \delta_{v}}{\delta}\left[\frac{f\left(\varepsilon_{j} \lambda / \delta\right)}{1-F\left(\varepsilon_{i} \lambda / \delta\right)}-\frac{\varepsilon_{i} \lambda}{\delta}\right]
$$

where $\lambda=\sigma_{u} / \sigma_{v}, \sigma^{2}=\sigma_{u}^{2}+\sigma_{v}^{2}$ while $f$ and $F$ represent the standard normal density and cumulative distribution function, respectively, evaluated at $\varepsilon_{j} \lambda / \sigma$.

The farm-specific technical efficiency is defined in terms of observed output $\left(Y_{i}\right)$ to the corresponding frontier output $\left(Y_{i}^{*}\right)$ using the available technology derived from the result of the Eq. 2 above as: 


$$
\mathrm{TE}_{i}=\frac{Y_{i}}{Y_{i}^{*}}=\frac{E\left(Y_{i} / U_{i}, X_{i}\right)}{E\left(Y_{i} / U_{i}=0, X_{i}\right)}=E\left[\exp \left(-U_{i}\right) / \varepsilon_{i}\right]
$$

TE takes value on the interval $(0,1)$, where 1 indicates a fully efficient farm.

Using a linear representation the empirical function to be estimated is written as:

$$
\operatorname{Ln} Y_{i}=\beta_{0}+\beta_{1} \operatorname{lnLab}{ }_{i}+\beta_{2} \operatorname{lnFrmsze}_{i}+\beta_{3} \operatorname{lnOxen}_{i}+\beta_{4} \operatorname{lnSD}_{i}+\beta_{5} \operatorname{lnDAP}_{i}+\beta_{6} \operatorname{lnUREA}_{i}+v_{i}-\mu_{i}
$$

where the subscript $i$, indicates the $i$ th household in the sample $(i=1, \ldots, \ldots, 150)$; $\ln$ is the natural logarithm (i.e., logarithm to base $e$ ); $\beta_{k}$ are parameters (elasticities) to be estimated $(K=1, \ldots, 6)$. The parameters $v$ and $\mu$ represent the stochastic and inefficiency components of the error term, respectively; and the other variables are as defined above. In this study, the half-normal distribution is assumed for the asymmetric technical inefficiency parameter.

The maximum likelihood estimates for the parameters of the stochastic frontier are obtained using the FRONTIER 4.1 (Coelli 1996) computer program, in which the variance parameters are expressed in terms of

$$
\begin{aligned}
& \sigma^{2}=\delta_{v}^{2}+\delta_{\mu}^{2} \text { and } \\
& \gamma=\sigma_{\mu}^{2} /\left(\sigma_{v}^{2}+\sigma_{\mu}^{2}\right)
\end{aligned}
$$

where $\sigma^{2}$ is the total variance of the model and the term $\gamma$ represents the ratio of the variance of inefficiency's error term to the total variance of the two error terms defined above. The value of variance parameter $\gamma$ ranges between 0 and 1 .

\subsection{Technical inefficiency effect model}

The estimates for all parameters of the stochastic frontier and inefficiency effect model were estimated in a single stage using the maximum likelihood (ML) method with the help of computer software package FRONTIER 4.1 (Coelli 1996).

The $\mu_{i}^{\prime} \mathrm{s}$ in equation were non-negative random variables, assumed to be independently distributed such that the technical inefficiency effect for the $i$ th farmer, $\mu_{i}$, were obtained by truncation of normal distribution with mean zero and variance, $\sigma_{\mu}^{2}$, such that

$$
\begin{aligned}
\mu_{i}= & \delta_{0}+\delta_{1 i}\left(\text { Age }_{i}\right)+\delta_{2 i}\left(\text { Educ }_{i}\right)+\delta_{3 i}\left(\text { HHsze }_{i}\right)+\delta_{4 i}\left(\text { Variety }_{i}\right) \\
& +\delta_{5 i}\left(\text { DAPtime }_{i}\right)+\delta_{6 i}\left(\text { Urea }_{i}\right)+\delta_{7 i}\left(\text { SDtime }_{i}\right)+\delta_{8 i}\left(\text { Soilcsn }_{i}\right) \\
& +\delta_{9 i}\left(\text { Frqcnt }_{i}\right)+\delta_{10 i}\left(\text { Trngprdn }_{i}\right)+\delta_{11 i}\left(\text { Trngmkt }_{i}\right)+\delta_{12 i}\left(\text { Credit }_{i}\right) \\
& +\delta_{13 i}\left(\text { Dismkt }_{i}\right)+\delta_{14 i}\left(\text { TLU }_{i}\right)+\delta_{15 i}\left(\text { Off }_{i}\right)+\omega_{i}
\end{aligned}
$$

The subscript $i$, indicates the $i$ th household in the sample $(i=1, \ldots, 150)$; $\delta_{0}, \delta_{1 i}, \ldots, \delta_{15 i}$ are parameters to be estimated. Age represents the age of the household head in number of years; Educ represents the educational level of the household head if 1 the household head was literate and 0 otherwise; Frqcnt represents frequency of extension contact, measured by the number of extension visits by extension agents; HHsze represents the number of household size; Off represents the households off-farm income 1 if the household members involved in non-farm activities, 0 otherwise; Variety 
represents potato seed varieties 1 if the household used improved variety seed, 0 otherwise; Soilcsn represents soil conservation activities that build farm plot 1 if the household practice soil conservation, 0 otherwise; Trngprdn and Trngmkt represents training of household heads related to potato production and marketing 1 if the farmer get training on potato production and marketing, 0 otherwise; Credit represents access to credit for potato production 1 if the household received credit, 0 otherwise; TLU represents the total number of livestock holding for the $i$ th household in TLU and Dismkt represents distance of the nearest output and input market in $\mathrm{km}$; DAPtime represents availability of DAP on time 1 if the household heads got DAP on time, 0 otherwise, Ureatime represents availability of Urea on time 1 if the household heads got Urea on time, 0 otherwise, and SDtime represents availability of seed on time 1 if the household heads got seed on time, 0 otherwise.

\section{Results and discussion}

\subsection{Descriptive statistics of respondents}

Table 2 presents characteristics with respect to sex, age, household size and educational level. In terms of sex, about $92 \%$ of the respondents were males. Regarding educational level, $28 \%$ of the farmers in Chilga district were illiterate and $72 \%$ of farmers were literate. Education plays an important role in enabling farmers to make informed decisions based on production process. The mean age of the household heads in the sample was 46.69 years with standard deviation of 10.82 . This implies that majority of the farmers are still in their active age and thus expected to be productive. Labor is the most important input for potato production, especially with respect to small-scale farmers. The results show that the average household size was 7.56 with the standard deviation 1.95, which mathematically represent 8 members per household. So, the household size plays an important role in potato production and most farmers depend mainly on family labor.

As indicated below Table 3 the mean yield of potatoes produced by household was approximately $13,108 \mathrm{~kg}$ per ha with a standard deviation of 6750.78 . These results suggest that there is considerable room for improving average potato yields in the study area. The average DAP and urea used by household was 227.68 and $160.53 \mathrm{~kg} / \mathrm{ha}$. The

Table 2 Demographic characteristics of the sample households. Source: Computed from Field Survey Data, 2015/16

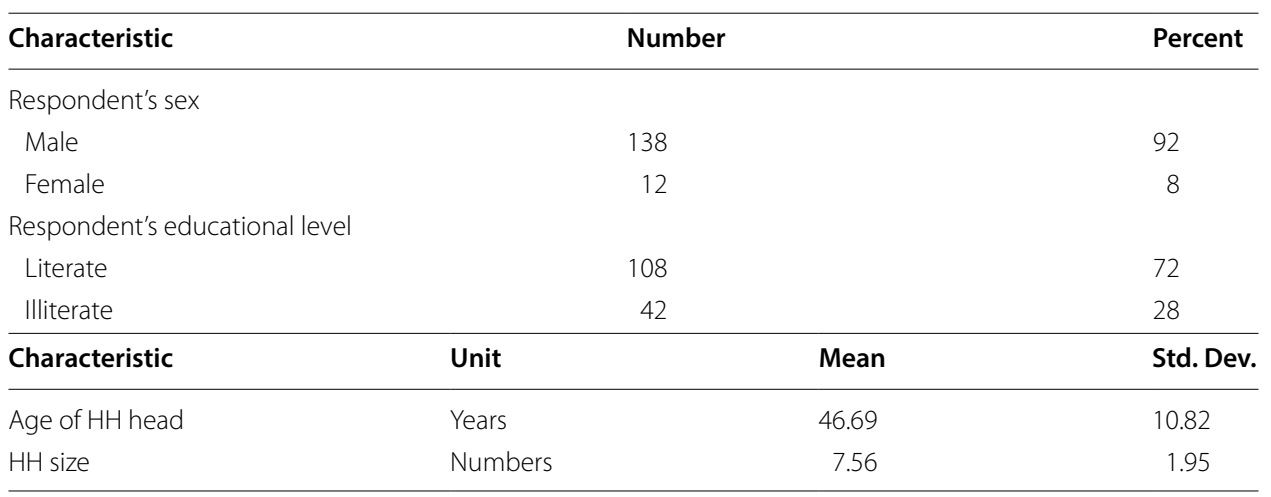


Table 3 Summary statistics of variables for stochastic production function analysis. Source: Computed from Field Survey Data, 2015/16

\begin{tabular}{llrr}
\hline Variables & Number & Mean & Std. Dev. \\
\hline Output (kg/ha) & 150 & $13,108.09$ & 6750.78 \\
Plot size (ha) & 150 & 0.20 & 0.11 \\
Labor (man-day/ha) & 150 & 295.97 & 327.15 \\
Seed (kg/ha) & 150 & 1884.76 & 1629.46 \\
DAP (kg/ha) & 150 & 227.68 & 102.77 \\
Urea (kg/ha) & 150 & 160.53 & 92.58 \\
Oxen (oxen-day/ha) & 150 & 121.35 & 127.51 \\
\hline
\end{tabular}

Table 4 VIF of the explanatory variables of the stochastic frontier production function model. Source: Computed from Field Survey Data, 2015/16

\begin{tabular}{lcc}
\hline Variables & VIF & $\mathbf{1 / V I F}$ \\
\hline LnUrea & 2.00 & 0.50 \\
LnDAP & 1.97 & 0.51 \\
LnMDE & 1.61 & 0.62 \\
LnPlot & 1.39 & 0.72 \\
LnODE & 1.27 & 0.79 \\
LnSD & 1.10 & 0.91 \\
Mean VIF & 1.56 & \\
\hline
\end{tabular}

average quantity falls below the recommended fertilizer quantity of $500 \mathrm{~kg} / \mathrm{ha}$ of Diammonium phosphate.

The quantity of seed per ha is an important variable, which might cause considerable variation in yield per ha and the average quantity of seeds per ha planted in the study area by the household was $1884.76 \mathrm{~kg} / \mathrm{ha}$. Average labor and oxen use were $295.97 \mathrm{man}-$ days/ha and 121.35 oxen-day/ha, respectively. The mean land size of the household was 0.2 ha with a standard deviation of 0.11 .

\subsection{Estimation of technical efficiency}

In this study, individual farmer's technical efficiency in potato production was estimated. Prior to the estimation of Stochastic Frontier Production Function Model and technical inefficiency model, continuous variables selected for estimation were checked for the problem of multicollinearity using Variance Inflation Factor (VIF) (Tables 4 and 5, respectively). Value of VIF more than 10 is usually considered as an indicator of serious multicollinearity (Gujarati 2006). Regarding the categorical variables, contingency coefficient, which is a Chi-square $\left(\chi^{2}\right)$-based measure of association, was employed to heck for the presence of multicollinearity (Table 6). A contingency coefficient value of 0.75 and above (i.e $\geq 0.75$ ) indicates the existence of a stronger relationship between the variables. By looking the contents of the table, it can be concluded that there is no problem of association among the variables as the respective coefficients are very low. Consequently, all the discrete variables were included in the estimation of the specified multiple linear regression models. 
Table 5 VIF for the continuous variables used to technical inefficiency model $(n=150)$ Source: Computed from Field Survey Data, 2015/16

\begin{tabular}{lcc}
\hline Variables & VIF & $\mathbf{1} / \mathbf{V I F}$ \\
\hline Age & 1.10 & 0.91 \\
HHsize & 1.05 & 0.95 \\
TLU & 1.20 & 0.83 \\
Dismkt & 1.12 & 0.90 \\
Freqcnt & 1.02 & 0.98 \\
Mean VIF & 1.10 &
\end{tabular}

Table 6 Contingency coefficients for hypothesized discrete explanatory variables $(n=150)$ Source: Computed from Field Survey Data, 2015/16

\begin{tabular}{|c|c|c|c|c|c|c|c|c|c|c|}
\hline & Educ & Variety & DAPtime & Ureatime & SDtime & Soilcsn & Tngprdn & Trngmkt & Credit & Off \\
\hline Educ & 1 & 0.096 & 0.014 & 0.023 & 0.121 & 0.098 & 0.049 & 0.106 & 0.043 & 0.244 \\
\hline Variety & & 1 & 0.212 & 0.101 & 0.221 & 0.229 & 0.216 & 0.080 & 0.306 & 0.330 \\
\hline DAPtme & & & 1 & 0.476 & 0.108 & 0.339 & 0.148 & 0.026 & 0.247 & 0.248 \\
\hline Ureatme & & & & 1 & 0.102 & 0.086 & 0.025 & 0.054 & 0.022 & 0.013 \\
\hline SDtime & & & & & 1 & 0.007 & 0.099 & 0.063 & 0.022 & 0.066 \\
\hline Soilcsn & & & & & & 1 & 0.248 & 0.060 & 0.348 & 0.257 \\
\hline Trngpdn & & & & & & & 1 & 0.273 & 0.242 & 0.323 \\
\hline Trngmkt & & & & & & & & 1 & 0.181 & 0.041 \\
\hline Credit & & & & & & & & & 1 & 0.297 \\
\hline Off & & & & & & & & & & 1 \\
\hline
\end{tabular}

The first null hypothesis tested is, the test for the existence of the inefficiency component of the composed error term of the stochastic frontier model. This is made to decide whether the traditional average production function (OLS) best fits the data set as compared to the stochastic frontier model (SFM) selected for this study. If the null hypothesis $H_{0}: \gamma=\delta_{0}=\delta_{1}=\cdots=\delta_{15}=0$ is accepted against alternative hypothesis $H_{1}: \gamma=\delta_{0}=\delta_{1}=\cdots=\delta_{15} \neq 0$, then the SFM is identical to OLS specification indicating that there is no inefficiency problem within the potato output households. This implies that the inefficiency effects do not depend on the household-specific variables and any deviation in observed potato output from the maximum possible potato output is because of statistical noise than any other specific factors. The null hypothesis is thus rejected at one degrees of freedom and 5\% significance level. The generalized log-likelihood ratio (LR) statistics, defined by equation $\left\{\mathrm{LR}=-2\left[\ln \mathrm{L}\left(H_{0}\right)-\ln \mathrm{L}\left(H_{1}\right)\right]\right\}$ was used to test the validity of the stochastic frontier production function over the ordinary least squares model. Under the null hypothesis $\left(H_{0}\right)$, the value of the restricted log-likelihood function for the ordinary least squares production function is -121.34498 , while under the alternative hypothesis $\left(H_{1}\right)$ for the stochastic Cobb-Douglas function, the value of the unrestricted log likelihood function is -91.273621 . This implies that the generalized likelihood-ratio (LR) statistic for testing the absence of technical inefficiency effect from the frontier is calculated to be. $L R=-2 *(-121.34498+91.273621)=60$. This value exceeds the critical $x^{2}(5 \%, 1)$ value of 3.84 at $5 \%$ level of significance in Table 7 . Thus, the null hypothesis was not accepted indicating that the stochastic frontier production 
Table 7 Summary of the test of hypothesis. Source: Computed from Field Survey Data, 2015/16

\begin{tabular}{lllll}
\hline Null hypothesis & Degree of freedom & LR & $\boldsymbol{x}^{\mathbf{2}}$ value & Decision \\
\hline$H_{0}: \gamma=0$ & 1 & 60 & 3.84 & Not accepted \\
$H_{0}: \beta_{7}=\cdots=\beta_{27}=0$ & 21 & 8.6 & 32.67 & Accepted \\
$H_{0}: \delta_{0}=\cdots=\delta_{15}$ & 15 & 46.36 & 25 & Not accepted \\
\hline
\end{tabular}

At $5 \%$ significance level

function was an adequate representation of the data, given the corresponding ordinary least squares production function. Hence, stochastic frontier approach best fits the data under consideration.

The second null hypothesis tested was, test for the selection of the appropriate functional form for the data; Cobb-Douglas versus Translog production function the decision to select functional form depends on the calculated (generalized) likelihood ratio. To select the appropriate specification, both Cobb-Douglas and Translog functional forms were estimated in Table 7. $\mathrm{LR}=-2 *(-91.273621+86.972011)=8.6$. The calculated Log likelihood Ratio (LR) is equal to 8.6 and the critical value of $x^{2}$ at 21 degree of freedom and 5\% significance level is 32.67 in Table 7. Thus, the null hypothesis that all coefficients of the interaction terms in Translog specification are equal to zero was accepted. This implies that the Cobb-Douglas functional form adequately represents the data under consideration. Hence, the Cobb-Douglas functional form was used to estimate the technical efficiency of the sample households in the study area.

The third null hypothesis explored is that farm-level technical inefficiencies are not affected by the farm and farmer-specific variables, and/or socio-economic variables included in the inefficiency model, i.e., $H_{0}: \delta_{0}=\delta_{1}=\cdots=\delta_{15}=0$. The inefficiency effect was calculated using the value of the Log-Likelihood function under the stochastic production function model (a model without explanatory variables of inefficiency effects: $H_{0}$ ) and the full frontier model (a model with explanatory variables that are supposed to determine inefficiency of each: $\left.H_{1}\right)$. $\{\mathrm{LR}=-2[-114.45496+91.273621=46.36]\}$. The calculated LR value of 46.36 was greater than the critical value of 25 at 15 degree of freedom, this shows that the null hypothesis $\left(H_{0}\right)$ that explanatory variables are simultaneously equal to zero was not accepted at $5 \%$ significance level. Hence, these variables simultaneously explain the sources of efficiency differences among the sample households.

Table 8 shows the results of simultaneously estimated stochastic frontier function and inefficiency effects model using Frontier 4.1C program. The maximum likelihood (ML) estimates of the parameter of the stochastic frontier Cobb-Douglas production function results are shown below in Table 8. The standard ordinary least squares (OLS) estimate is also presented for comparison. The technical efficiency analysis of potato production revealed that there was presence of technical inefficiency effects in potato production in the study area as confirmed by the gamma value of 0.99 that was significance at $1 \%$ level. The gamma $(\gamma)$ (which is the ratio of the variance of the inefficiency component to the total error term) value of 0.99 implies that about $99 \%$ variation in the output of potato farmers was due to differences in their technical efficiencies (the total variation in output is due to existence of production inefficiency). By implication about $1 \%$ 
Table 8 The econometric parameters estimation results of the C-D and OLS. Source: Computed from Field Survey Data, 2015/16

\begin{tabular}{|c|c|c|c|c|c|}
\hline \multirow[t]{2}{*}{ Variable } & \multirow[t]{2}{*}{ Parameter } & \multicolumn{2}{|c|}{ Ordinary least squares } & \multicolumn{2}{|c|}{ Maximum likelihood estimate } \\
\hline & & Coefficient & $t$-ratio & Coefficient & $t$-ratio \\
\hline Intercept & $\beta_{0}$ & 6.85 & $8.43^{* * *}$ & 13.21 & $72.79^{* * *}$ \\
\hline LnArea & $\beta_{1}$ & 0.17 & 1.64 & 0.05 & 0.36 \\
\hline LnDAP & $\beta_{2}$ & 0.14 & 1.01 & 0.13 & $2.62^{* *}$ \\
\hline LnUREA & $\beta_{3}$ & 0.05 & 0.42 & -0.05 & -0.72 \\
\hline LnODE & $\beta_{4}$ & 0.19 & $2.93^{* * *}$ & 0.16 & $3.54^{* * *}$ \\
\hline LnMDE & $\beta_{5}$ & -0.08 & -1.26 & -0.038 & $-3.11^{* * *}$ \\
\hline LnSD & $\beta_{6}$ & 0.18 & $2.04^{* *}$ & -0.515 & $-5.97^{* * *}$ \\
\hline \multicolumn{6}{|l|}{ Inefficiency effect model } \\
\hline Constant & & & & 18.29 & $8.28^{* * *}$ \\
\hline Age & & & & -8.32 & $-7.21^{* * *}$ \\
\hline Educ & & & & 0.05 & 0.23 \\
\hline HHsze & & & & -0.06 & -0.27 \\
\hline Variety & & & & -0.28 & $-1.67^{*}$ \\
\hline DAPtime & & & & -0.33 & -1.45 \\
\hline Ureatime & & & & 0.07 & 0.27 \\
\hline SDtime & & & & -0.06 & -0.305 \\
\hline Soilcsn & & & & -0.14 & -0.66 \\
\hline Freqcnt & & & & 0.06 & 0.53 \\
\hline Trngprdn & & & & 0.19 & 1.13 \\
\hline Trngmkt & & & & -0.099 & -0.38 \\
\hline Credit & & & & 0.075 & 0.41 \\
\hline Dismkt & & & & 0.54 & $3.26^{* * *}$ \\
\hline TLU & & & & 0.12 & 0.81 \\
\hline Off & & & & 0.12 & 0.59 \\
\hline \multicolumn{6}{|l|}{ Variance parameters } \\
\hline Sigma-squared & $\sigma^{2}$ & & & 0.37 & $6.51^{* * *}$ \\
\hline Gamma & $\Gamma$ & & & 0.99 & $59,138,266^{* * *}$ \\
\hline Log likelihood function & & -121.34498 & & -91.273621 & \\
\hline $\mathrm{LR}$ & & & & 60.142728 & \\
\hline Return to scale & & & & -0.263 & \\
\hline Total sample size & $N$ & 150 & & 150 & \\
\hline
\end{tabular}

***, ${ }^{* *}$ and * represents significance at $1 \%, 5 \%$ and $10 \%$ probability levels, respectively

of the variation in output among producers is due to random factors such as unfavorable weather, effect of pest and diseases, errors in data collection and aggregation and the like. The $(\gamma)$ parameter is very important because it shows the relative magnitude of the inefficiency variance associated with the frontier model which assumes that there is no room for inefficiency in the model. The estimated elasticity of mean output means with respect to DAP, ODE, MDE and seed were $0.13,0.16,0.038$ and 0.515 , respectively. These coefficients represent percentage change in dependent variable as a result of percentage change in the independent variables.

Oxen power-days: variable was found to be an important variable for the production of potato and with the expected sign and statistically significant at $1 \%$ probability level. The positive coefficient shows that an increase in the number of oxen-days in 
the course of land preparation through collecting by $1 \%$ will tend to increase potato yield by $0.16 \%$; other variables in the model remain constant. It is the second critical variable, which affect the level of potato output given DAP, MDE and amount of seed kept constant. Thus, oxen availability is crucial to increase technical efficiency in potato production in the study areas. This finding is similar with Asefa (2011), Abebe (2014) and Ahmed et al. (2014).

Seed elasticity of potato output has the unexpected sign but statistically significant and $1 \%$ increase in seed will decrease potato output by $0.52 \%$, ceteris paribus. This is due to the fact that yield depends on the number of plants per ha and population of plants is directly related to the appropriate quantity of seed used. Moreover, negative and significant elasticity for seed in potato production indicates that there is a reduction of output when it applied more than the recommended quantity of seed. Because a very high seed density may result in low potato output due to high competition for nutrients. This finding is similar with Ahmed et al. (2013) and Kassa (2017).

The findings of the study that labor hours is negatively related to potato output. Therefore, a percent increase in labor hours spent on farms will reduce potato output by $0.038 \%$. If farm laborers spend more hours on their farms without efficiently performing their work, then output will fall. The reason is that during ridging time, farmers hire labors because ridging need more time, and in the study area ridging applied three times so as to minimize food competition for potato and weed. This was due to poor managerial ability to effectively utilize the available labor force in the household and hired. But this depends fundamentally on two factors, namely; the number of people in a household and hired who can actually work on the farm and the length of time for which each member are prepared to work on the household and hired farm or may be due to competition and over exploitation of farm land. Consequently, what matters is not the number of the household and hired per se, but the composition and quality of those capable of working on the farm. This is consistent with some findings Hossain et al. (2008).

The elasticity of DAP shows 0.13 , DAP was found positively significant at $5 \%$ level. This implies that DAP is sensitive towards the production of potato, since a $1 \%$ increase will lead to $0.13 \%$ increase in potato production. This implies that DAP is an important factor of production for potato. The results concur with the findings of other studies such as Bizuayehu (2014), Kitila and Alemu (2014).

The coefficient of the dummy representing use of improved seeds was statistically significant at $10 \%$. Thus, production of potato through the use of more of improved potato seeds was more efficient compared to using local seeds. Moreover, the negative sign of the estimated coefficients had important implications on the technical efficiency of the potato producers in the study area. It means that the tendency for any potato producers to increase their production depend on the type and quality of improved seed available at the right time of sowing. The indication that technical efficiency and use of improved seed were positively correlated was in consonance with prior expectation and consistent with findings by Tesfaye (2013), Jwanya et al. (2014) and Deressa et al. (2017).

The age of the household influenced inefficiency negatively. This suggested that older farmers were more efficient than their young counterparts. The reason for this was probably because the farmers become more skill full as they grow older due to cumulative farming experiences. Moreover increase in farming experiences leads to a better 
assessment of the important and complexities of good farming decision-making including efficient use of input. Similar conclusions were made by Omonona et al. (2010) and Tesfaye (2013).

The positive coefficient of household distance to the market implies that an in increase in this variable would lead to increase in the level of technical inefficiency. Similar conclusions were made by Asogwa et al. (2011).

\subsection{Technical efficiency analysis}

The maximum likelihood estimates of the Cobb-Douglas stochastic production function coefficients, which are presented in Table 9, are used to predict the technical efficiencies of the sample individual firms. The results of efficiency analysis revealed that technical efficiency of the smallholder potato household varied from a minimum of $3.16 \%$ to a maximum of $99 \%$ with a mean of $46 \%$. In other words, on average smallholder potato producer households in the study area incur a $54 \%$ loss in output due to technical inefficiency. This implies that on average output can be increased by at least $54 \%$ while utilizing existing resources and technology if inefficiency factors are fully addressed or more precisely, on the average, output can be expanded by as much as $54 \%$ if appropriate measures are taken to improve technical efficiency. The wide variation in technical efficiency estimates is an indication that farmers are still using their resources inefficiently in the production process and there still exists opportunities for improving on their current level of technical efficiency. This result suggests that a few households were not utilizing their production resources efficiently, indicating that they were not obtaining maximum output from their given quantity of inputs.

Another implication of this result is that if the average farmer in the sample were to achieve the technical efficiency (TE) level of the most efficient counterpart, then the average farmer could realize an 53.5\% cost savings [i.e., $(1-(46 / 99)) * 100$ ] in terms of total production costs and maximizing their potato productivity. Thus, sample households could on average, reduce production cost by $53.5 \%$ by reducing input applications to the technically efficient input mix. A similar calculation for the most technically inefficient household reveals a cost saving of $96.8 \%$ [i.e., $(1-(3.16 / 99)) * 100]$. Therefore in short run, it is possible to reduce production cost in potato production in the study area by an average of $96.8 \%$ by adopting the technology and techniques used by the best

Table 9 Frequency distribution of technical efficiency of potato producers. Source: Computed from Field Survey Data, 2015/16

\begin{tabular}{llc}
\hline TE level & Frequency & Percent \\
\hline $0.03-0.20$ & 25 & 16.67 \\
$0.20-0.40$ & 48 & 32.00 \\
$0.40-0.60$ & 38 & 25.33 \\
$0.60-0.80$ & 24 & 16.00 \\
$0.80-1$ & 15 & 10.00 \\
Total & 150 & 100 \\
Mean & 0.46 & \\
Minimum & 0.03 & \\
Maximum & 0.99 & \\
\hline
\end{tabular}




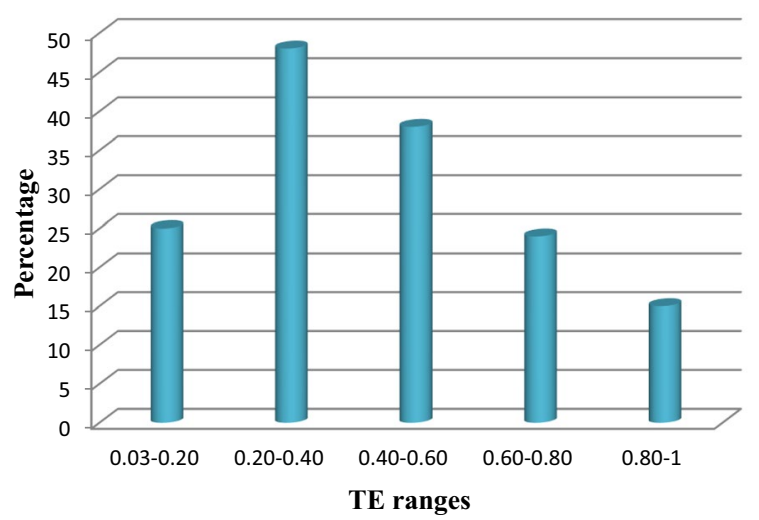

Fig. 2 Frequency distribution of technical efficiency (Source: Computed from Field Survey Data, 2015/16)

performers. Improved efficiency would reduce production costs and increase the gross margin of potato production and enhance profitability.

To give a better indication of the distribution of the technical efficiencies, a frequency distribution of the predicted technical efficiencies is presented in Fig. 2. The frequencies of occurrences of the predicted technical efficiencies in range indicate that the highest number of household have technical efficiencies between 0.20 and 0.40 . The sample frequency distribution indicates a clustering of technical efficiencies in the region 0.20 0.40 efficiency ranges, representing $48 \%$ of the respondents. The findings also reveal that there is a huge gap between the least technically efficient and the most technically efficient farmers in the study area.

\subsection{Yield gap due to technical inefficiency}

Yield gap may be defined as the difference between technically full efficient yield and observed yield. Therefore, yield gap is the amount which represents fewer yields due to technical inefficiency. From the Stochastic model defined in Eq. (3), TE of the $i$ th household is estimated to be:

$$
\mathrm{TE}_{i}=\frac{Y_{i}}{Y_{i}^{*}}=\frac{f\left(X_{i} ; \beta\right) \exp \left(v_{i}-\mu_{i}\right)}{f\left(X_{i} ; \beta\right) \exp \left(v_{i}\right)}=\exp \left(-\mu_{i}\right)
$$

Then, solving for $Y_{i}^{*}$, the potential yield of each household is represented as:

$$
Y_{i}^{*}=\frac{Y_{i}}{\mathrm{TE}_{i}}=f\left(X_{i} ; \beta\right) \exp \left(v_{i}\right)
$$

where $\mathrm{TE}_{i}$ is the technical efficiency of the $i$ th sample household in potato production; $Y_{i}^{*}$ is the frontier/potential output of the $i$ th sample household in potato production, and $Y_{i}$ is the actual/observed output of the $i$ th sample household in potato production.

Based on equation above and using the values of the actual potato output obtained and the predicted technical efficiency indices, the potential potato output was estimated for 
Table 10 Potato yield gap due to technical inefficiency. Source: Computed from Field Survey Data, 2015/16

\begin{tabular}{lllll}
\hline Variable & Min & Max & Mean & Std. Dev. \\
\hline Actual yield (kg/ha) & 1000 & 36,000 & $13,108.09$ & 6750.775 \\
TE estimates & 0.0316 & 0.9996 & 0.456563 & 0.2505988 \\
Potential/frontier yield (kg/ha) & 8047.12 & $63,675.64$ & $30,890.52$ & 8198.517 \\
Yield gap/loss (kg/ha) & 8.005598 & $53,435.64$ & $17,782.43$ & $11,266.49$ \\
\hline
\end{tabular}

each sample household in potato production on hectare basis. The mean result is presented in Table 10 below.

It was observed that mean technical inefficiency was $54 \%$ which caused $17,782.43 \mathrm{~kg} /$ ha yield gap of potato on the average with mean value of the actual output and the potential output of $13,108.09 \mathrm{~kg} / \mathrm{ha}$ and $30,890.52 \mathrm{~kg} / \mathrm{ha}$, respectively. This shows that sample households in study area were producing on the average $17,782.43 \mathrm{~kg} / \mathrm{ha}$ lower potato output than their potential yield.

The mean levels of both the actual and potential output during the production year were $13,108.09 \mathrm{~kg} / \mathrm{ha}$ and $30,890.52 \mathrm{~kg} / \mathrm{ha}$, with the standard error of 6750.775 and 8198.517, respectively. Figure 3 illustrates that under the existing practices there is a room to increase potato yield following the best-practiced farms in the study area.

\section{Conclusions and recommendations}

Both descriptive and econometric methods were used to analyze the data in this study. Hypotheses tests confirm the adequacy of Cobb-Douglas frontier over Translog frontier for the data; the appropriateness of using stochastic frontier production function over convectional production function and decreasing returns to scale nature of the stochastic frontier production function. The findings of the estimation revealed that four inputs

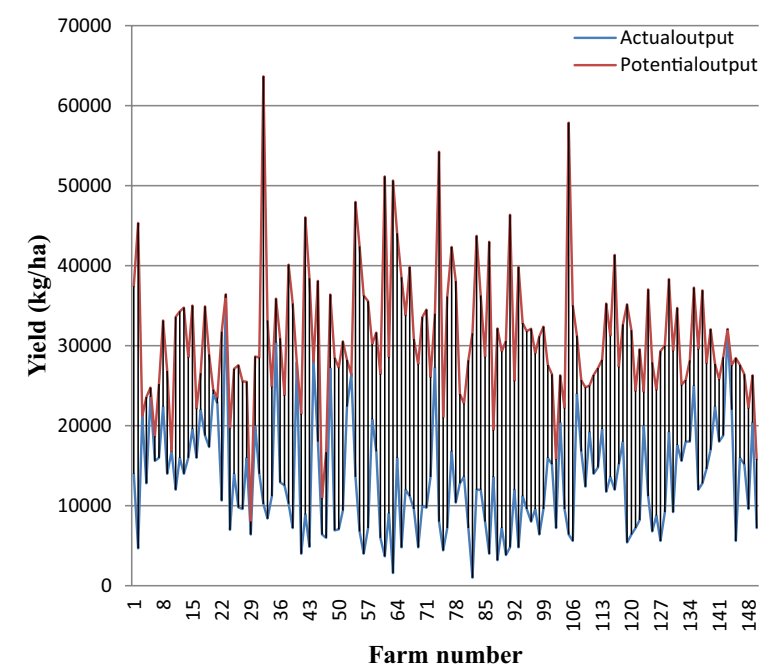

Fig. 3 Comparison of the actual and the potential level of yield (Source: Computed from Field Survey Data, 2015/16) 
were significant in potato production function. Out of six input variables, four input variables which are DAP, oxen, MDE and seed statistically significant in the frontier model. DAP and oxen positively affected potato production. The positive coefficient of these parameters indicates that increased use of these inputs will increase the production level to greater extent. MDE and seed negatively affected potato production. Hence if inputs are used to their maximum potential, there will be considerable gain from improvement in technical efficiency. The estimated SPF model together with the inefficiency parameters shows that age and improved seed variety were influenced inefficiency negatively whereas distance to market was increase the level of technical inefficiency. Based on the findings, the followings recommendations are forwarded: Improved potato seed need to be supplied in sufficient amount and on time at reasonable price regularly to improve farmers' efficiency in the production of potato and to meet the increasing potato demand for increased population. The government and any concerned bodies should give more emphasis on rural infrastructures like road so as to transact market for any time. Younger producers were less efficient than older ones. Hence, the government and any concerned bodies should give continuous trainings on the agricultural production and marketing for younger producers.

\begin{abstract}
Abbreviations
ARARI: Amhara Regional Agricultural Research Institute; C-D: Cobb-Douglas; CDFEDO: Chilga District Finance and Economic Development Office; CSA: Central Statistical Authority; DA: Development Agent; DAP: Di Ammonium Phosphate; ECA: Eastern and Central Africa; EIAR: Ethiopian Agricultural Research Institute; FAO: Food and Agriculture Organization; KA: Kebele Administration; Ln: Natural logarithm; LR: Log likelihood ratio; MDE: Man Day Equivalent; MLE: Maximum likelihood estimator; NGOs: Non-Governmental Organizations; ODE: Oxen Day Equivalent; OLS: Ordinary least squares; SFM: Stochastic frontier model; SSA: Sub-Saharan Africa; TE: Technical efficiency; TLU: Tropical Livestock Unit; VIF: Variance Inflation Factor.
\end{abstract}

\title{
Acknowledgements
}

We are grateful for the University of Gondar for funding this study. We are also very grateful for Chilga District administrative for their cooperation during data collection and providing supplementary secondary data. Last but not least, we thank the respondents of this study for their time and willingness in providing data.

\section{Authors' contributions}

All authors had their own crucial role in the process of completing this study. Study design, data collection, and data analysis, critically review and provide comments on the content and structure of the paper. All authors read and approved the final manuscript.

\section{Funding}

This work was supported by the University of Gondar.

\section{Availability of data and materials}

All authors declare that the data sets used in this manuscript are fully available upon request from the corresponding author.

\section{Competing interests}

The authors declare that they have no competing interests.

Received: 21 August 2019 Revised: 7 October 2019 Accepted: 16 October 2019

Published online: 05 November 2019

\section{References}

Abate TM, Dessie AB, Mekie TM (2019) Technical efficiency of smallholder farmers in red pepper production in North Gondar zone Amhara regional state, Ethiopia. J Econ Struct. https://doi.org/10.1186/s40008-019-0150-6

Abebe GG (2014) Off-farm income and technical efficiency of smallholder farmers in Ethiopia: a stochastic frontier analysis. An M.Sc. Thesis presented to Swedish University of Agricultural Sciences (SLU)

Ahmad B, Abedullah, Bakhsh K (2006) Technical efficiency and its determinants in potato production, evidence from Punjab, Pakistan. Lahore J Econ 11(2):1-22

Ahmed B, Haji J, Geta E (2013) Analysis of farm households' technical efficiency in production of smallholder farmers: the case of Girawa District, Ethiopia. American-Eurasian J Agric Environ Sci 13(12):1615-1621 
Ahmed MH, Lemma Z, Endrias G (2014) Technical efficiency of maize producing farmers in Arsi Negelle Central Rift Valley of Ethiopia stochastic frontier approach. Agric For 60(1):157-167

Asefa S (2011) Analysis of technical efficiency of crop producing smallholder farmers in Tigray, Ethiopia. An M.Sc. Thesis Presented to School of Graduate Studies in Mekelle University

Aseyehegn K, Yirga C, Rajan S (2012) Effect of small scale irrigation on the income of rural farm households: the case of Laelay Maichew District, central Tigray, Ethiopia. J Agric Sci 7(1):43-57

Asogwa BC, Umeh JC, Penda ST (2011) Analysis of economic efficiency of Nigerian small scale farmers: a parametric frontier approach. J Econ 2(2):89-98

Bizuayehu S (2014) Technical efficiency of major crops in Ethiopia. Acad J Agric Res 2(6):147-153

Bravo-Ureta BE, Pinheiro AE (1997) Technical, economic and allocative efficiency in peasant farming: evidence from the Dominican Republic. Dev Econ 34:48-67

Chilga District Finance and Economic Development Office, 2014. Annual Report

Coelli TJ (1996) A guide to FRONTIER version 4.1: a computer program for frontier production and cost function estimation, CEPA Working paper 96/07, University of New England, Armidale

CSA (Central Statistical Agency) (2009) Agricultural sample survey. Addis Ababa, Ethiopia

CSA (Central Statistical Agency) (2011) Agriculture in figures, on key finding of the 2008/09-2010/11, agricultural sample surveys for all sectors and seasons

CSA (Central Statistical Agency) (2014) Agricultural sample survey; Addis Ababa, Ethiopia

Demelash N (2015) Deficit irrigation scheduling for potato production in North Gondar Ethiopia. Afr J Agric Res. https:// doi.org/10.5897/AJAR2013.6961

Deressa B, Garoma D, Sekhara Reddy OC, Alemu B (2017) Analysis of technical efficiency of potato (Solanum tuberosum) production: in the case of Welmera Districts, Oromia Regional State, Ethiopia. Int J Basic Appl Sci 7(1):43-56

Dube AK, Ozkan B, Ayele A, Idahe D, Aliye A (2018) Technical efficiency and profitability of potato production by smallholder farmers: the case of Dinsho District, Bale Zone of Ethiopia. J Dev Agric Econ 10(July):225-235. https://doi. org/10.5897/JDAE2017.0890

EIAR and ARARI (2013) Seed potato tuber production and dissemination experiences, challenges and prospects: proceedings of the national workshop on seed potato tuber production and dissemination, 12-14 March 2012, Bahir Dar, Ethiopia. www.sweetpotatoknowledge.org

FAO, 2010. Food and Agriculture Organization of the United Nations, FAOSTAT database. Accessible online

Gildemacher PR, Maina P, Nyongesa M, Kinyae P, Gebremedhin W, Lema Y, Damene B, Shiferaw T, Kakuhenzire R, Kashaija I, Musoke C, Mudiope J, Kahiu I, Ortiz O (2009) Participatory analysis of the potato knowledge and information system in Ethiopia, Kenya and Uganda. In: Sanginga PC, Waters-Bayer A, Kaaria S, Njuki J, Wettasinha C (eds) Innovation Africa: enriching farmers'livelihoods. Earthscan, London, pp 153-167

Global Hunger Index (2013) The challenge of hunger: building resilience to achieve food and nutrition security. Washington, DC, Bonn, and Dublin, October 2013

Gujarati DN (2006) Basic econometrics, 4th edn. Tata McGraw-Hill, New Delhi

Hirpa A, Meuwissen MP, Tesfaye A, Lommen WJ, Lansink AO, Tsegaye A, Struik PC (2010) Analysis of seed potato systems in Ethiopia. Am Potato Res J 87:537-552

Hossain MA, Hasan MK, Naher Q (2008) Assessment of technical efficiency of potato producers in some selected areas of Bangladesh. J Agric Rural Dev 6(1\&2):113-118

Jondrow J, Lovell CAK, Materov IS, Schmidt P (1982) On the estimation of technical efficiency in the stochastic frontier production function model. J Econom 19(2-3):233-238

Jwanya BA, Dawang NC, Mashat IM, Gojing BS (2014) Technical efficiency of rain-fed Irish potato farmers in Plateau State, Nigeria: a stochastic frontier approach. Dev Ctry Stud. IISTE ISSN 2224-607X (Paper) ISSN 2225-0565. 4:22

Kassa Y (2017) Determinants of technical efficiency in maize production of smallholder farmers; the case of Fogera District, South Gondar Zone, Ethiopia. An M.Sc. Thesis presented to School of Graduate Studies in University of Gondar

Kitila GM, Alemu BA (2014) Analysis of technical efficiency of small holder maize growing farmers of Horo Guduru Wollega Zone, Ethiopia: a stochastic frontier approach. Sci Technol Arts Res J 3(3):204-212

Kothari CR (2004) Research methodology: methods and techniques, 2nd edn. New Age International, New Delhi

Leavy A, Matthews A, O'Neill S (1999) Farm technical efficiency and extension. Economic Papers 9912, Dublin: Economics Department, Trinity College

Mulatu E, Ibrahim O, Bekele E (2005) Policy challenges to improve vegetable production and seed supply in Hararghe, Eastern Ethiopia. Veg Sci J 11(2):81-106

Omonona BT, Egbetokun OA, Akanbi AT (2010) Farmers resource use and technical efficiency in cowpea production in Nigeria. Department of Agricultural Economics, University of Ibadan, Ibadan, Oyo State, Nigeria. Econ Anal Policy 40(1):87

Scott JS, Rosegrant MW, Ringler C (2000) Roots and tubers for the 21st century: trends, projections and policy options. Food, Agriculture and the Environment Discussion Paper 31, IFPRI, pp 64

Tesfaye W (2013) Determinants of technical efficiency in maize production: the case of smallholder farmers in Dhidhessa District, Illubabor Zone, Ethiopia. A M.Sc. Thesis presented to School of Graduate Studies of Haramya University

Tiruneh WG, Chindi A, Woldegiorgis G (2017) Technical efficiency determinants of potato production: a study of rain-fed and irrigated smallholder farmers in Welmera district, Oromia, Ethiopia. J Dev Agric Econ 9(8):217-223. https://doi. org/10.5897/JDAE2016.0794

UNDP Global HDR (2014) Human development report. United Nations Development Programme, New York. http://hdr. undp.org/sites/default/files/hdr14-report-en-1.pdf

Wilson P, Hadley D (1998) Measuring and explaining technical efficiency in UK potato production. J Agric Econ 49(3):294-305

\section{Publisher's Note}

Springer Nature remains neutral with regard to jurisdictional claims in published maps and institutional affiliations. 